\title{
Pelatihan Pembuatan Herbarium Sebagai Media Pembejalaran di Sekolah Bagi Guru MTs Dharut Tayyibin Batu Jai Kabupaten Lombok Barat
}

\author{
Sri Nopita Primawati ${ }^{1^{*}}$, Baiq Muli Harisanti ${ }^{2}$, Septiana Dwi Utami $^{3}$, \\ Ika Nurani Dewi ${ }^{4}$, Sumarjan ${ }^{5}$ \\ ${ }^{1 *, 2,3,4}$ Program Studi Pendidikan Biologi, FSTT, UNDIKMA \\ ${ }^{5}$ Fakultas Pertanian, UNRAM \\ Corresponding Author: srinopitaprimawati@ikipmataram.ac.id
}

\begin{abstract}
This community service activity aims to increase the teacher's knowledge of herbarirum learning media, and in the end the teacher can make a herbarium that can be used in the biology learning process. The main target of this dedication is biology teachers at MTs Dharut Tayyibin Batu Jai. The activity method in the form of training was then followed by making a herbarium from plants and samples brought by students from their homes or their neighborhoods. Based on the results of the evaluation and the responses of the teacher and students, they showed great enthusiasm for the activity and it was proven by the participation of students and teachers until this activity was completed. The teacher as the main target shows that their ability to make herbarium increases, the herbarium made with students can be used as biology learning that supports the learning process. The MTs students who participated in this process were very enthusiastic and active because it was such a fun new thing. It is hoped that in the future this training activity should be carried out not only in making herbariums but in making other creative learning media. The goal is to help students understand biology material and make biology lessons more fun.
\end{abstract}

\begin{abstract}
Abstrak: Kegiatan pengabdian kepada masyarakat ini bertujuan untuk menambahkan oengetahuan guru tentang media pembelajaran herbarirum, serta pada akhirnya guru dapat membuat herbarium yang dapat digunakan dalam proses pembelajaran biologi. Sasaran utama dari pengabdian ini adalah guruguru biologi di MTs Dharut Tayyibin Batu Jai. Metode kegiatan berupa pelatihan kemudian dilanjutkan dengan pembuatan herbarium dari tanaman dan sampel yang dibawa oleh siswa-siswi dari rumah atau lingkungan sekitar tempat tinggalnya. Berdasarkan hasil evaluasi dan respon guru dan siswa menunjukkan antusias yang besar terhadap kegiatan serta dibuktikannya dengan partisipasi siswa dan guru hingga kegiatan ini selesai. Guru sebagai sasaran utama menunjukkan kemampuan membuat herbariumnya meningkat, herbarium yang dibuat bersama siswa dapat digunakan sebagai pembelajaran biologi yang mendukung proses pembelajaran. Siswa-siswi MTs yang ikut serta dalam proses ini sangat antusias dan aktif karena ini merupakan hal baru yang menyenangkan. Diharapkan kedepannya kegiatan pelatihan ini hendaknya dilakukan bukan hanya pada pembuatan herbarium namun pada pembuatan media pembelajaran kreatif lainnya. Tujuannya membantu siswa dalam memahami materi biologi dan membuat pelajaran biologi lebih menyenangkan.
\end{abstract}

How to Cite: Primawati, S., Harisanti, B., Utami, S., Dewi, I., \& Sumarjan, S. (2021). Pelatihan Pembuatan Herbarium Sebagai Media Pembejalaran di Sekolah Bagi Guru MTs Dharut Tayyibin Batu Jai Kabupaten Lombok Barat. Jurnal Pengabdian UNDIKMA, 2(1), 43-49. doi:https://doi.org/10.33394/jpu.v2i1.3726

This is an open-access article under the CC-BY-SA License.

\author{
Article History: \\ Received: 10-03-2021 \\ Reviewed: 14-04-2021 \\ Accepted: 21-04-2021 \\ Published: 05-05-2021
}

Sejarah Artikel:

Diterima: 10-03-2021

Direview: 14-04-2021

Disetujui: 21-04-2021

Diterbitkan: 05-05-2021

\section{Kata Kunci: \\ Pelatihan, Herbarium, Media Pembelajaran, Biologi.}




\section{Pendahuluan}

Peningkatan mutu pendidikan merupakan prioritas utama dalam penyelenggaraan pendidikan. Pemerintah melalui Kementerian Pendidikan Nasional telah berupaya meningkatkan mutu pendidikan melalui penyelenggaraan pendidikan yang berkualitas. Diantaranya dengan melakukan perbaikan sistem pendidikan di daerah seperti penyempurnaan kurikulum, peningkatan profesinalisme guru, khususnya pada mata pelajaran Biologi, pengadaan buku mata pelajaran, perbaikan sarana dan prasarana serta peningkatan kemampuan mengajar guru dengan menerapkan variasi strategi serta model-model pembelajaran yang menuntut siswa belajar lebih aktif (Fadhli, 2017).

Peningkatan profesionalisme guru ini menuntut guru lebih kreatif dan inovatif dalam mempersiapkan diri dan siswa dalam menempuh proses pembelajaran. Hal ini karena guru memegang peranan penting dalam peningkatan kualitas siswa dalam proses pembelajaran. Guru harus benar-benar memperhatikan, memikirkan dan sekaligus merencanakan proses belajar mengajar yang inovatif kreatif serta berpusat pada siswa. Siswa dituntut untuk langsung melakukan observasi, mengukur, menyusun variable membuat kesimpulan dari setiap pengamatan dan sebagainya.

Media pembelajaran merupakan salah satu komponen penting dalam pembelajaran IPA. Media merupakan alat bantu untuk memahami konsep atau materi pelajaran. Biologi merupakan salah satu bagian dari IPA (sains) yang menerapakan konsep-konsep ilmiah serta mengembangkan keterampilan proses sains. Keterampilan proses sians dapat dimiliki siswa melalui pengamatan langsung terhadap objek yang melibatkan berbagai aktivitas siswa di kelas maupun di luar kelas (Supardi, 2017).

Keterbatasan sarana dan prasana merupakan salah satu alasan ketidak profesionalan guru sebagai tenaga pengajar. Namun dengan tuntutan dunia saat ini mengharuskan siswa dan guru berpikir kreatif dan inovatif sehingga diperlukan suatu solusi untuk menyelesaikan masalah pendidikan tersebut. Salah satu solusi yang dapat diaplikasikan dengan penggunaan media pembelajaran. Media pembelajaran sendiri dapat bersifat visual, audio maupun audiovisual dengan tujuan memudahkan siswa untuk memahami materi yang disampaikan guru. Diharapkan media pembelajaran yang berasal dari lingkungan sekolah dan tempat tinggal siswa dapat digunakan guru dalam menjelaskan beberapa konsep dalam materi pembelajaran biologi.

Untuk meningkatkan kemampuan guru dalam membuat media pembelajaran maka diadakan pelatihan pembuatan herbarium bagi guru-guru MTs Dharut Thayyibin. Tujuan untuk melatih dan membekali keterampilan bagi guru-guru dalam membuat herbarium yang sangat penting sebagai media pembelajaran khususnya dalam kegiatan praktikum di sekolah.

\section{Metode Pengabdian}

Pelatihan pembuatan herbarium bagi Guru MTs Dharut Tayyibin Batu Jai di lakukan selama bulan 1 bulan di MTs Dharut Tayyibin Batu Jai kabupaten Lombok Tengah yang diikuti oleh para guru dan siswa yang sedang mengampu mata pelajaran keanekaragam mahluk hidup. Metode pendekatan kegiatan berupa pelatihan kemudian dilanjutkan dengan pembuatan herbarium kering dari tanaman dan sampel yang dibawa oleh siswa-siswi dari rumah atau lingkungan sekitar tempat tinggalnya. Adapun rinciannya sebagai berikut:

Koordinasi Kegiatan

Tahan-tahap koordinasi kegiatan ini meliputi sosialisasi dan Pendekatan dengan guru dan siswa di MTs Dharut Tayyibin Batu Jai dengan tujuan menemukan solusi dari 
permasalahan yang disampaikan. Selain itu guru akan mengatur jadwal pelaksanaan agar disesuaikan dengan jadwal pelajaran siswa dan tim pengabdian, tempat pelaksanaan dan mekanisme pelaksanaan kegiatan. Setelah menetukan waktu guru dan tim pengabdian akan mempersiapkan alat dan bahan yang dibutuhkan selama pengabdian berlangsung seperti : alcohol, semprotan atau baskom, kertas koran, kertas dan kertas mika, benang jahit, isolatif dan label.

\section{Pelaksanaan}

Adapun tahap-tahap pelaksanaan kegiatan pengabdian ini meliputi :

a) Tahap Pendahuluan

Tahap pendahuluan ini dilakukan dengan beberapa kegiatan yaitu (1). Registrasi awal peserta yaitu siswa dan guru kelas 7 MTs Dharut Tayyibin Batu Jai di ruang kelas; (2).Pembukaan oleh MC; (3). Pembacaan doa untuk kelancaran pelatihan; (4). Sambutan ketua pengabdian; (5). Sambutan dan pemberian materi berupa pembuatan herbarium dari jenis-jenis tanaman yang sering ditemukan di lingkungan siswa dan memberikan contoh herbarum yang telah dibuat oleh narasumber.

b) Tahapan Inti

Tahapan inti dari pelatihan herbarum ini adalah pembuatan herbarium yang dilakukan oleh siswa dan guru. Guru aka membagi siswa menjadi 3 kelompok. Siswa membawa tanaman dari rumah mereka dari akar sampai kedaun dan batang. Adapun tahap-tahap pembutan herbarium meliputi : (1). Pilihlah tumbuhan yang akan diawetkan. Bentuk dan jenis tumbuhan bisa mengikuti kebutuhan. Jika anda ingin mengoleksi tumbuhan dengan struktur yang lengkap maka anda bisa memilih rerumputan yang memiliki bunga dan berukuran tidak terlalu Semprot bahan yang akan diawetkan dengan alkohol $70 \%$. Gunanya agar tumbuhan tidak mudah busuk oleh bakteri dan jamur. (2). Letakkan calon awetan yang telah disemprot alkohol tadi di atas koran dengan posisi yang rapih. Untuk membentuk agar tampak lebih rapih kita bisa mengikat ranting menggunakan benang dan dan menjahitnya pada kertas sesuai keinginan. (3). Tutup bahan dengan koran. (4). Tindih atau jepit kuat bahan yang telah terbungkus koran dengan kayu atau bambu. Nah selanjutnya bahan yang telah kita proses ini disebut dengan istilah specimen. (5). Simpan spesimen selama 1 sampai 2 minggu di tempat kering dan tidak lembab. (6). Jika sudah dirasa kering, keluarkan spesimen dari bungkusan kertas koran. (7). Letakkan spesimen di atas kertas karton dengan rapih lalu rekatkan dengan isolatif transparan. (8). Buat judul herbarium yang kamu miliki dan berikan keterangan-keterangan yang akan memperjelas bagian-bagian tumbuhan yang kamu awetkan. (9). Agar lebih awet dan tampak lebih indah, kita bisa membuat dan memasukkan herbarium ke dalam bingkai sederhana dengan kardus dan plastik mika (Inan, 2016).

c) Tahap Evaluasi

Setelah dilakukan pengabdian dalam bentuk pelatihan pembuatan herbarium sebagai media pembejalaran di sekolah bagi guru Mts Dharut Tayyibin Batu Jai Lombok Barat NTB perlu diadakan evaluasi untuk mengetahui apakah kegiatan berhasil dalam tujuan utamanya. Evaluasi ini dilakukan dengan tahapan observasi sebelum kegiatan dan setelah kegiatan. Selain itu dilihat dari produk herbarium yang dihasilkan. 


\section{Hasil Pengabdian dan Pembahasan}

Kegiatan pengabdian ini dilakukan selama 1 bulan di sekolah MTs Dharut Tayyibin Batu Jai dengan melibatkan semua guru IPA dan siswa kelas 7 yang sedang menempuh mata pelajaran keanekaragaman hayati. Berdasarkan wawancara, tanya jawab dan pengamatan langsung selama kegiatan berlangsung, kegiatan pengabdian pada masyarakat ini memberikan hasil sebagai berikut:

Meningkatnya Pengetahuan dan Pemahaman Guru dan Siswa Biologi MTs Dharut Thayyibin dalam Merancang dan Membuat Media Pembelajaran Biologi

Pemberian materi di lakukan oleh tim pengabdian dimulai dari media pembelajar IPA, meliputi tujuan utama media pembelajaran adalah mengefektifkan proses komunikasi pembelajaran sehingga tercapai tujuan pembelajaran yang diinginkan. Pentingnya sebuah media pembelajaran agar dapat memperlancar kegiatan pembelajaran dan memudahkan siswa untuk memahami materi ajar (Munadi, 2010). Terlihat dari pemaparan ini guru mulai bertanya aktif tengtang jenis-jenis media pembelajaran dan kesulitan yang dalami selama proses pembelajaran. Guru menjelaskan bahwan kurangnya ketersediaan alat-alat laboratorium biologi di sekolah menyebabkan siswa selama ini hanya menfaatkan buku paket sebagai acuan belajar. Kreatifitas dan keterbatasan pemahaman guru juga menyebabkan siswa sulit memahami pelajaran biologi dan bosan selama proses pembelajaran di kelas.

Selama proses pemberian materi juga di jelaskan tentang beberapa media pendidikan yang sering dipergunakan dalam pembelajaran IPA diantaranya media cetak, elektronik, model dan peta konsep. Media cetak banyak dipergunakan untuk pembelajaran dalam menjelaskan materi pelajaran yang kompleks sebagai pendukung buku ajar. Pembelajaran dengan menggunakan media cetak akan lebih efektif jika bahan ajar sudah dipersiapkan dengan baik yang dapat memberikan kemudahan dalam menjelaskan konsep yang diinginkan kepada siswa. Media elektronik seperti video banyak dipergunakan di dalam pembelajaran IPA. Penggunaan video sangat baik dipergunakan untuk membantu pembelajaran, terutama untuk memberikan penekanan pada materi pelajaran yang sangat penting untuk diketahui oleh siswa.

Dengan penjelasan yang beragam tentang media pembelajaran IPA guru dapat menambah pengetahuan dan mulai berkreasi dalam proses belajar mengajar. Selain guru juga siswa sanat focus mendengarkan arahan dari pemateri. Siswa terlihat sangat antusias karena melihat herbarium yang sudah jadi dibawa ke sekolah sebagai contoh herbarium yang benar.

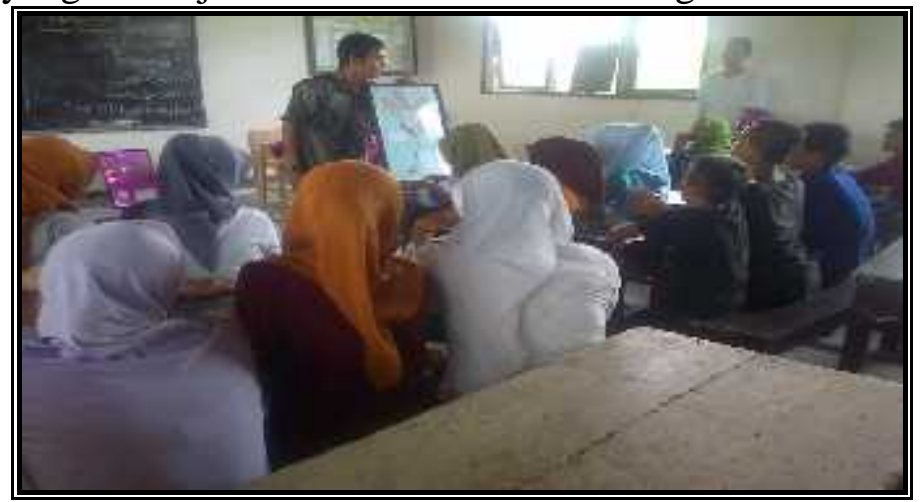

Gambar 1. Pemberian Materi Herbarium dan Memberikan Contoh Herbarium

Terdapat beberapa komentar yang disampaikan oleh Guru dan siswa selama pemberian materi ini. Salah satunya adalah herbarium adalah bentuk yang paling sederhana dari media pembelajaran yang bisa menggunakan ketersedian bahan yang ada dilingkungan 
sekitar tanpa membutuhkan alat ataupun media yang belum bisa disiapkan oleh sekolah. Di sekolah MTs Dharut Tayyibin Batu Jai belum terdapat ruangan khusus sebagai laboratorium biologi, sehingga tidak terdapat alat peraga lain yang dimilii oleh guru untuk membantu proses pembelajaran. Untuk media video atau yang menggunakan computer sebagai alat kerjanya guru sangat terbatas, hanya beberapa yang memiliki namun banyak yang tidak. Tim melihat kemampuan ini disebabkan keterbatasan secara ekonomi dari sekolah dan guru. Namun untuk mendukung akriditasi sekolah media pembelajaran ini sangat dibutukan dan memiliki nilai penting. Oleh sebab itu guru sangat berterima kasih dengan di adakannya pelatihan ini di sekolah mereka.

\section{Meningkatnya Keterampilan Guru Biologi MTs Dharut Thayyibin dalam Pembuatan Herbarium}

Setelah pelatihan dan materi pembuatan herbarium di jelaskan sebelumnya masuklah tahap pembuatan herbarium. Pembuatan herbarium ini dilakukan oleh siswa dan guru mereka. Siswa membawa specimen yaitu tumbuhan yang berada disekitar lingkungan rumah atau pun sekolah. Guru bersama siswa dan ditemani oleh tim memulai pembuatan herbarium. Alat dan bahan yang telah disiapkan di ambil oleh setiap kelompok siswa yang ditemani oleh 1 guru dan tim pengabdian.

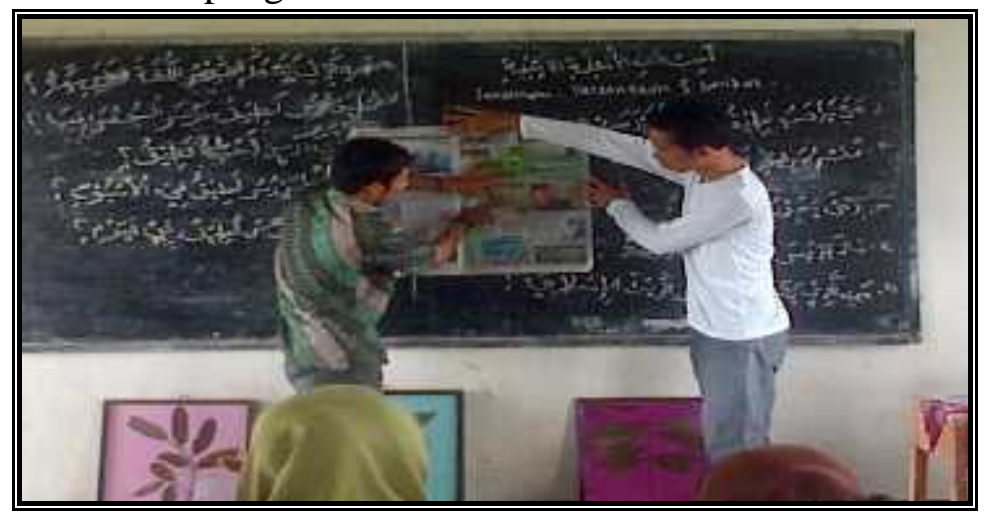

Gambar 2. Tim Pengabdian Menjelaskan Mekanisme Pembuatan Herbarium

Awalnya tim akan memperagakan cara membuat herbarium yaitu dengan memilih tumbuhan yang akan diawetkan. Bentuk dan jenis tumbuhan bisa mengikuti kebutuhan. Jika anda ingin mengoleksi tumbuhan dengan struktur yang lengkap maka anda bisa memilih rerumputan yang memiliki bunga dan berukuran tidak terlalu besar. Setelah itu semprot bahan yang akan diawetkan dengan alkohol $70 \%$. Gunanya agar tumbuhan tidak mudah busuk oleh bakteri dan jamur. Kemudian diletakkan awetan yang telah disemprot alkohol tadi di atas koran dengan posisi yang rapih. Untuk membentuk agar tampak lebih rapih kita bisa mengikat ranting menggunakan benang dan dan menjahitnya pada kertas sesuai keinginan. Kemdian ditutup bahan dengan koran. ditindih atau jepit kuat bahan yang telah terbungkus koran dengan kayu atau bambu. Selanjutnya bahan yang telah kita proses ini disebut dengan istilah specimen. Specimen yang telah dibuat disimpan selama 1 sampai 2 minggu di tempat kering dan tidak lembab. Selama proses pengeringan ini specimen disimpan di sekolah tepatnya di ruang guru agar tidak rusak ataupun terbuang. Sampai tahap ini proses diberhentikan hingga specimen kering, dan akan di adakan pelatihan lagi setelah 2 minggu. Diharapkan selama 2 minggu specimen tersebut akan kering dan siap untuk di percantik sebagai herbarium. 


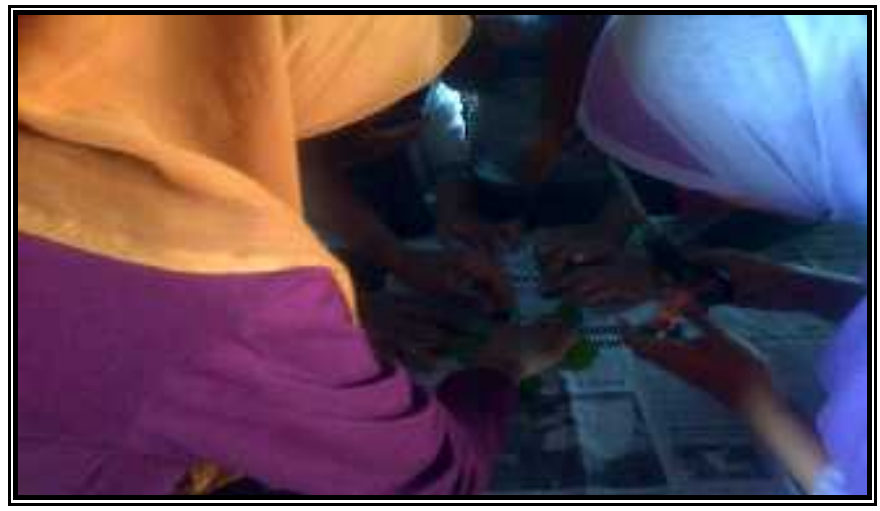

\section{Gambar 3. Siswa dan Guru Sedang Berlatih Membuat Herbarium}

Setelah 2 minggu siswa, guru dan tim pengabdian mengadakan pertemuan kembali atau disebut pelatihan ke 2 dengan agenda mellihat specimen yang sudah kering dan mempercantik herbarium tersebuut. Spesiem tersebut kering maka di keluarkan dari bungkusan kertas koran. Kemudian specimen tersebut diletakkan di atas kertas karton dengan rapih lalu di rekatkan dengan isolatif transparan. Setelah itu setiap siswa dan guru membuat judul herbarium yang di miliki dan berikan keterangan-keterangan yang akan memperjelas bagian-bagian tumbuhan yang diawetkan. Agar lebih awet dan tampak lebih indah, siswa dan guru bisa membuat dan memasukkan herbarium ke dalam bingkai sederhana dengan kardus dan plastik mika.

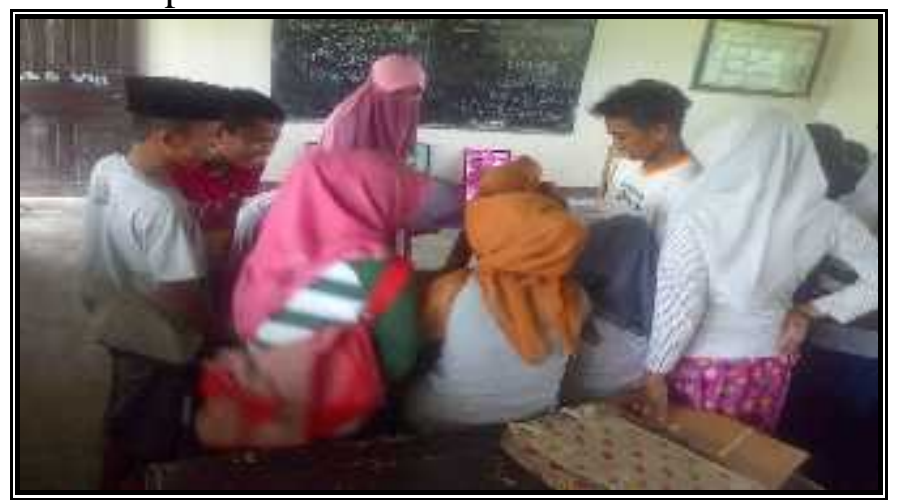

\section{Gambar 4. Siswa dan Guru Ikut Berperan Aktif dalam Pembuatan Herbarium}

Siswa sangat menikmati proses pembuatan herbarium dengan bimbingan dari tim dan guru mereka tidak rebut, bekerja secara kelompok dan bertanya langsung jika kurang paham. Selama proses ini memang guru dan tim mengajarkan mereka untuk bertanggung jawab atas herbarium yan mereka buat per kelompok. Sehingga hamper tiap hari mereka masuk ruang guru untuk menanyakan herbarium mereka dan melihat apakah ada serangga atau hewan kecil yang merusak herbarium mereka. Dengan sikap ini guru merasa siswa memiliki tanggung jawab dan disiplin karena siswa ingin menunjukkan pada guru mereka kalu mereka akan membuat herbarium yang bagus.

Guru di sekolah mereka mengatakan bagi siapa yang herbariumnya terbaik maka akan dibingkai dan digunakan selama proses pembelajaran biologi untuk materi keanekaragam hayati. Dari 3 kelompok semua herbariumnya berhasil dibuat dengan jenis tanaman yang berbeda-beda. Diharapkan proses pelatihan hingga pembuatan herbarium ini dapat diajadikan pengalam menarik bagi guru dan siswa serta menjadi solusi dari keterbatasa mereka selama ini dalam memenuhi kebutuhan media pembelajaran IPA. 
Herbarium yang telah dibuat oleh guru dan siswa digunakan sekolah sebagai media pembelajaran yang memiliki nilai lebih untuk pengajuan akriditasi sekolah. Media pembelajaran merupakan point penting dalam akriditasi sekolah karena termasuk dalam media yang membantu proses pembelajaran. Kreatifitas guru dalam menyediakan media yang membantu dalam proses pembelajaran di sekolah yang terbatas mendapat poin lebih dalam pengajuan akriditasi sekolah.

\section{Kesimpulan}

Dari kegiatan pengabdian pada masyarakat ini dapat disimpulkan bahwa: (1) Pengetahuan dan pemahaman guru biologi dan siswa MTs Dharut Thayyibin dalam merancang dan membuat media pembelajaran yaitu herbarium menjadi meningkat. (2) Keterampilan guruguru biologi dan siswa MTs Dharut Thayyibin dalam pembuatan herbarium meningkat.

\section{Saran}

Mengingat besarnya manfaat kegiatan pengabdian pada masyarakat ini, maka saran yang perlu disampaikan yakni: (1) Mengadakan pelatihan serupa pada spesimen makhluk hidup yang berbeda serta khalayak sasaran yang berbeda pula serta wilayah jangkauan MTs yang lebih luas. (2) Adanya kesinambungan dan monitoring program pasca kegiatan pengabdian ini sehingga guru-guru biologi MTs Dharut Thayyibin benar-benar dapat mempraktekkan pembuatan herbarium ini di sekolah.

\section{Daftar Pustaka}

Arsyad, A. (2002). Media Pengajaran. Jakarta: PT Raja Grafindo Persada.

Ayati, O., dan Iswari, M., 2019. Keterampilan membuat Herbarium kering melalui Model Pembelajaran Explicit Instruction bagi Anak Tunagrahita. Jurnal Penelitian Pendidikan Khusus 7(1).

Fadhli, M. (2017). Manajemen Peningkatan Mutu Pendidikan. Jurnal Studi Manajemen Pendidikan, 1(2).

Inan, K. (2016). Cara Membuat Herbarium ( Pengawetan spesimen Kering ) dengan Sederhana. https://www.inankito.org/2016/08/cara-membuat-herbarium.html. Di download pada 9 April 2021.

Mustami, K.M. 2009. Inovasi Model-Model Pembelajaran Bidang Sains Untuk Meningkatkan Hasil Belajar Mahasiswa. Lentera Pendidikan, vol 12(2).

Istiadah. FN., (2020). Teori-Teori Belajar Dalam Pendidikan. Jawa Barat : Edu Publisher

Supardi, K. (2017). Media Visual dan Pembelajaran IPA di Sekolah Dasar. Jurnal Inovasi Pendidikan Dasar, 1(2). 